\title{
Localized climate change scenarios of mean temperature and precipitation over Switzerland
}

\author{
Elias M. Zubler • Andreas M. Fischer • Mark A. Liniger • \\ Mischa Croci-Maspoli • Simon C. Scherrer • \\ Christof Appenzeller
}

Received: 29 May 2013 / Accepted: 4 May 2014 /Published online: 7 June 2014

(C) The Author(s) 2014. This article is published with open access at Springerlink.com

\begin{abstract}
There is a growing need of the climate change impact modeling and adaptation community to have more localized climate change scenario information available over complex topography such as in Switzerland. A gridded dataset of expected future climate change signals for seasonal averages of daily mean temperature and precipitation in Switzerland is presented. The basic scenarios are taken from the CH2011 initiative. In CH2011, a Bayesian framework was applied to obtain probabilistic scenarios for three regions within Switzerland. Here, the results for two additional Alpine sub-regions are presented. The regional estimates have then been downscaled onto a regular latitudelongitude grid with a resolution of $0.02^{\circ}$ or roughly $2 \mathrm{~km}$. The downscaling procedure is based on the spatial structure of the climate change signals as simulated by the underlying regional climate models and relies on a Kriging with external drift using height as auxiliary predictor. The considered emission scenarios are A1B, A2 and the mitigation scenario RCP3PD. The new dataset shows an expected warming of about 1 to $6^{\circ} \mathrm{C}$ until the end of the 21 st century, strongly depending on the scenario and the lead time. Owing to a large vertical gradient, the warming is about $1{ }^{\circ} \mathrm{C}$ stronger in the Alps than in the Swiss lowlands. In case of precipitation, the projection uncertainty is large and in most seasons precipitation can increase or decrease. In summer a distinct decrease of precipitation can be found, again strongly depending on the emission scenario.
\end{abstract}

Electronic supplementary material The online version of this article (doi:10.1007/s10584-014-1144-x) contains supplementary material, which is available to authorized users.

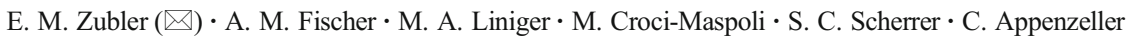
Office of Meteorology and Climatology MeteoSwiss, Federal Department of Home Affairs,

Operation Center 1, Zurich Airport, Postfach 257, 8058 Zurich, Switzerland

e-mail: elias.zubler@meteoswiss.ch

A. M. Fischer

e-mail: andreas.fischer@meteoswiss.ch

M. A. Liniger

e-mail: mark.liniger@meteoswiss.ch

M. Croci-Maspoli

e-mail: mischa.croci-maspoli@meteoswiss.ch

S. C. Scherrer

e-mail: simon.scherrer@meteoswiss.ch

C. Appenzeller

e-mail: christof.appenzeller@meteoswiss.ch 


\section{Motivation}

Owing to the location and complex topographic structure of Switzerland, many different climatic regions have been distinguished (Schüepp and Gensler 1980; Baeriswyl and Rebetez 1997; Begert 2008). Given this complexity, particularly with respect to precipitation patterns, one can expect that Switzerland may experience considerable spatial differences in the effects of climate change (Jasper et al. 2004).

Studies of past climate change in Switzerland have shown that temperatures rose about twice as fast as on average in the Northern Hemisphere with a mean trend of about $0.14{ }^{\circ} \mathrm{C}$ decade $^{-1}$ between 1864 and 2000 (Begert et al. 2005). This has been confirmed by (Rebetez and Reinhard 2011; Ceppi et al. 2012). For precipitation, significant trends have only been found during the winter season in the period 1864 to 2000 (Begert et al. 2005). The spatial variability of precipitation change is very large (Schmidli and Frei 2005).

Expected changes in future mean temperature and precipitation in Switzerland were recently estimated by (Fischer et al. 2012) in the framework of CH2011, a research initiative by the Center for Climate Systems Modeling (C2SM), MeteoSwiss, ETH Zurich and the Swiss Advisory Body on Climate Change (OcCC) (CH2011 2011). They used a Bayesian approach (Buser et al. 2009) to provide probabilistic climate change information based on 20 regional climate models that were run within the ENSEMBLES project following the A1B emission scenario (van der Linden and Mitchell 2009). (Fischer et al. 2012) suggest a temperature increase in Switzerland of about $3-$ $6{ }^{\circ} \mathrm{C}$ by the end of the century with respect to the reference period from 1980 to 2009 . They performed the probabilistic analysis for 3 different emission scenarios: the mitigation scenario RCP3PD during which emissions are reduced back to 1900 levels within the 21st century (Meinshausen et al. 2011), and the SRES scenarios A1B and A2 (Meehl et al. 2007). The latter is a strong business-as-usual scenario, whereas A1B assumes emission reductions as a consequence of technological progress in the second half of the 21st century. As the ENSEMBLES model simulations were restricted to the scenario A1B, the results for the other two emission scenarios were obtained by pattern-scaling using global mean temperature changes.

In their study, (Fischer et al. 2012) focused on the northern mainland of Switzerland and the Alpine south side and excluded the Alps from their analysis. This is a drawback for many applications. More recent studies show that some ENSEMBLES models predict an enhanced warming at higher elevations. This is likely related to the snow-albedo and other feedback mechanisms (Ceppi et al. 2012; Kotlarski et al. 2012a, b; Scherrer et al. 2012). The phenomenon has already been documented more than a decade earlier (Beniston and Rebetez 1996; Giorgi et al. 1997). The range of possible causes for an elevation-dependent warming has been reviewed by (Rangwala and Miller 2012).

In case of precipitation, there is much less confidence regarding the sign of the future changes. In winter, spring and fall precipitation can both increase or decrease. Only during summer a distinct drying was found (Fischer et al. 2012). Quantitatively however, the results strongly depend on the chosen scenario, the lead time, and the region within Switzerland.

A steadily growing community of climate impact modelers is interested in more localized climate data for both past and future in order to study complex local phenomena associated with climate change in Switzerland. Today, impact studies lack in high-resolution input data, both in terms of time and space (Köplin et al. 2010). Impact studies are of great importance to develop adaptation strategies for hydrology and glaciology, various economic sectors such as power production, forestry, agriculture and tourism and other aspects such as heat waves (Schär et al. 2004; Fischer and Schär 2010), drought, flood risk, snowfall level and permafrost stability (FOEN 2012).

Given the growing need for high-resolution climate change data for larger regions and for complex Alpine settings, we extended the approach of (Fischer et al. 2012) by two Alpine regions in order to provide full coverage of Switzerland with probabilistic climate change 
scenarios. We used the regional mean data from the Bayes calculations in combination with ENSEMBLES mean change patterns to generate spatially high-resolution climate change signals for seasonal mean temperature and precipitation given the three scenarios A1B, A2 and RCP3PD on a regular grid with a mesh size of $0.02 \times 0.02^{\circ}$ (roughly $2 \mathrm{~km}$ ), covering the whole of Switzerland. The downscaling method is based on a Kriging interpolation with external drift (Journel and Huijbregts 1978; Wackernagel 2003). It assumes that the localized change signal is the sum of a deterministic part (trend) and a stochastic part (kriged residuals), using the geographical coordinates latitude, longitude and height as linear predictors. Observations of temperature and precipitation dating back to 1961 and other quantities are available at MeteoSwiss on the same grid ((Frei 2013), e.g.).

The article is structured as follows: Section 2 describes the data and methods. Section 3 shows the results. The latter are then discussed in section 4. The data described in this article is applied in a second paper that focuses on changes in key climate indices over Switzerland (Zubler et al. 2014).

\section{Data and methodology}

In this section, the input data and the procedure used for spatial downscaling is explained. As for the methodology of the preceding steps, including the Bayesian algorithm, we only discuss some of the key aspects and refer to the comprehensive description of (Fischer et al. 2012) and (Buser et al. 2009) for details. First, an overview of the data is given in subsection 2.1. Subsection 2.2 describes the downscaling procedure. A proof of concept is given in subsection 2.3. Uncertainties of the downscaling method are discussed in subsection 2.4.

\subsection{Probabilistic projections}

The same selection of 20 regional climate models (RCM) from the ENSEMBLES project (van der Linden and Mitchell 2009) is used as in (Fischer et al. 2012). Each RCM is driven by a general circulation model (GCM). The RCMs have a horizontal resolution of $0.22^{\circ}$ (roughly $25 \mathrm{~km}$ in Switzerland). Owing to the fact that some of the ENSEMBLES simulations are computed on slightly different grids, the output of some models has been interpolated to the rotated grid used by most ENSEMBLES RCMs prior to further processing. The simulations span over a time period from 1950 to 2050, in case of 14 models even to 2100 . These GCMRCM chains (non-weighted) were subject to a joint probabilistic assessment based on the Bayesian algorithm of (Buser et al. 2009) and following the methodological procedures in practice described by (Fischer et al. 2012). The observational dataset E-OBS (version 3.0; (Haylock et al. 2008)), providing temperature and precipitation at daily resolution, is given on the same grid as the RCMs. E-OBS data is available for the period 1950-2010.

The method of (Fischer et al. 2012) consists of three major steps: (1) regional aggregation and data pre-processing including separation of trends and variability, (2) application of the Bayes-algorithm of (Buser et al. 2009) for the probabilistic calculations, and (3) postprocessing of the obtained probability density functions of climate change. As a first step in pre-processing, the seasonal mean time series of all models are regionally aggregated. Complementing the three regions from (Fischer et al. 2012), we compute the mean seasonal time series for two additional regions: the western Swiss Alps (CHAW) and the eastern Swiss Alps (CHAE). Figure 1a shows the orography of the E-OBS dataset as well as the grid-points belonging to each of the 5 regions. Figure $1 \mathrm{~b}$ shows the topography of the $0.02^{\circ}$ grid onto which the data are downscaled later. The manual choice of the two new regions is ultimately subjective, since full coverage of Switzerland is one of the prerequisites. Nevertheless, the 

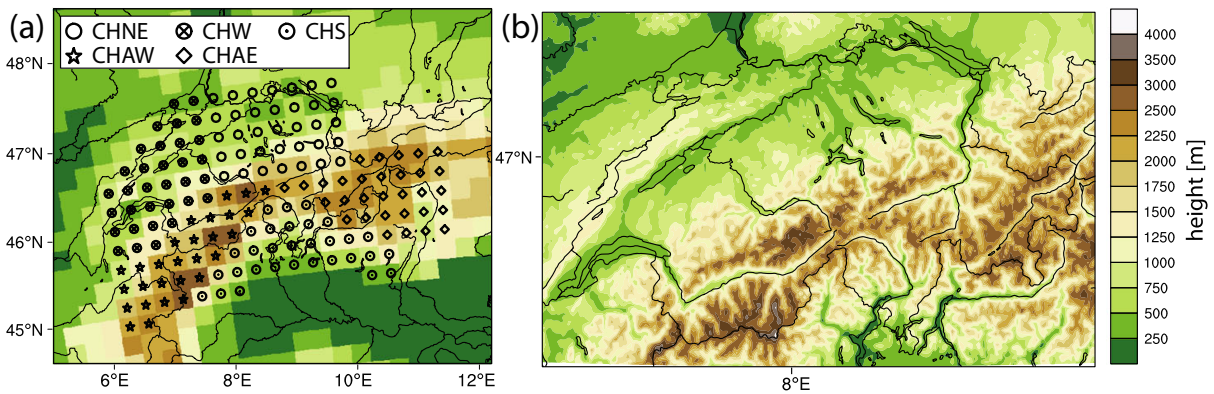

Fig. 1 a Topography of the E-OBS dataset and the grid points belonging to the five regions for which the Bayes algorithm was calculated: Northeastern Switzerland (CHNE), Western Switzerland (CHW), Southern Switzerland (CHS), Western Swiss Alps (CHAW) and Eastern Swiss Alps (CHAE). b Domain size and topography of the regular latitude-longitude grid with a resolution of $0.02 \times 0.02^{\circ}$

following criteria are fulfilled by this choice: all points within a region show similar climatological behavior with regard to long-term trends and interannual variability: the linear correlation coefficient of each gridpoint with the core region ( 9 grid points in the center of each region, not shown) is larger than 0.9 for temperature and 0.8 for precipitation. Furthermore, a separation into western and eastern Swiss Alps is justified based on cluster analyses of (Begert 2008). A second criterion concerns statistical robustness that should be met by including a sufficient number of grid points for each region. In our case, the number of grid points in the two Alpine regions is of the same order as the three regions chosen by (Fischer et al. 2012).

The regionally aggregated seasonal time series are then split into a slowly varying component assumed as climate change and the residual high-frequency fluctuations. The long-term trend is represented by a 4th-order polynomial fit. In a second step, decadal variability is removed from the time series exactly as in (Fischer et al. 2012). The 30-year fluctuations, here denoted as internal decadal variability, are removed from the residuals by taking a moving average with the corresponding window size. Since the Bayes-algorithm requires the data to be normally distributed, a square root transformation was performed on the precipitation values. As a final pre-processing step, the RCMs driven by the same GCM are averaged to meet the independence requirement of the Bayesian algorithm (Fischer et al. 2012).

The second major step in the method of (Fischer et al. 2012) is the application of the Bayesian algorithm of (Buser et al. 2009) to our pre-processed input data. Posterior distributions of several climate parameters (including the climate shift parameter) are calculated based on pre-specified prior distributions and based on a Markov chain Monte Carlo algorithm ((Casella and George 1992), e.g.).

Finally, the data have to be re-transformed and recombined with the previously removed decadal variability. For this purpose, internal variability is computed from observational data. EOBS, however, underestimates variability in comparison with the models (1950-2009), likely due to the fitting of a polynomial function to a much shorter time series than in case of the models. Therefore, we use observed data from a few single stations with long-term measurements considered representative for the corresponding region. The same has been done by (Fischer et al. 2012). Here, we take the mean over the stations Chateau d'Oex (CHD) and Gr. St. Bernhard (GSB) for the western Alps (CHAW) and Segl-Maria (SIA) and Davos (DAV) for the eastern Alpine region(CHAE) to compute decadal variability. These stations provide homogenized data that go back to 1864 (Begert et al. 2005). In case of CHAW, however, data is only used from 1918 to 2011, due to known quality problems of GSB before that date.

For the sake of brevity, the results for seasonal mean temperature and precipitation change from the Bayes-calculations for the two new regions are given as supplementary material to this article 
(Figures 1 and 2 of the Supplementary material). The three probabilistic estimates that are provided correspond to the $2.5 \%$-percentile (lower estimate), the median and the $97.5 \%$ percentile (upper estimate) of the posterior distributions. Figure 9 in the article of (Fischer et al. 2012) shows the same for the regions of Northeastern Switzerland (CHNE), Western Switzerland (CHW) and Southern Switzerland (CHS). The Alpine regions CHAW and CHAE show the strongest warming of the five regions in summer under the A1B and A2 scenario in the later periods (2045-74 and 2070-99). Model uncertainty, expressed by the spread between the lower and the upper estimate, is similar in all regions. The annual cycle shows a similar pattern with stronger warming in winter and summer as compared to spring and autumn. As an example, the projected warming in CHAW for the summer season in 2070-99 is $1.3-2.6{ }^{\circ} \mathrm{C}$ in RCP3PD, 3.3-5.8 ${ }^{\circ} \mathrm{C}$ in A1B and $3.9-6.7^{\circ} \mathrm{C}$ in $\mathrm{A} 2$.

A prominent feature in the projections from ENSEMBLES and the derived probabilistic estimates is a height-dependence of temperature change with an increased warming at higher altitudes (CH2011 2011; Kotlarski et al. 2012b). This is reflected by the regional estimates. The warming tends to be stronger in CHAW and CHAE than in the three non-Alpine regions with lower average height. For example, the median estimates of temperature change in 2020 $49(2045-74,2070-99)$ are about $0.05^{\circ} \mathrm{C}\left(0.15^{\circ} \mathrm{C}, 0.2^{\circ} \mathrm{C}\right)$ larger in winter and about $0.2^{\circ} \mathrm{C}$ $\left(0.4{ }^{\circ} \mathrm{C}, 0.4{ }^{\circ} \mathrm{C}\right)$ larger in summer. Note that these are only regional means. In the ENSEMBLES multi-model mean, an increased warming of more than $1{ }^{\circ} \mathrm{C}$ between the lowest and the highest points may be found, in particular towards the end of the century.

The precipitation change in the seasonal and regional mean also shows a similar pattern in all five regions. The drier conditions in summer are consistent for the periods 2045-74 and 2070-99 in A1B and A2. For example, a possible precipitation reduction by the end of the century of about $30 \%$ is found in A2. Note that in general, region CHAW has the smallest uncertainty range in precipitation. This is partly associated with the fact that in CHAW seasonal mean precipitation amounts are the largest and thus, variability in relative terms is smaller than in other regions.

A height-dependence of the precipitation change signal is also found in many seasons and projection periods. In winter, the ENSEMBLES mean shows a stronger increase in precipitation at low altitudes as compared to the Alpine region. For example, an increase of about $10 \%$ in winter is found for the Swiss lowlands, whereas in the Alps the precipitation does not change at all. Hence, the relative increase in winter precipitation from ENSEMBLES is expected to be smaller with increasing altitude. The opposite is found in summer, where a tendency towards a weaker drying with increasing altitude is found. Here, the lowest grid points in western Switzerland exhibit a drying of about $20 \%$ by the end of the century, whereas the drying at high altitudes hardly exceeds $10 \%$ relative to the reference period 1980 2009. These relationships with height can be again partly explained with the absolute amount of precipitation which increases with altitude as a consequence of orographic forcing and enhanced convection. In a recent study by (Fischer et al. 2014) it has also been shown that the distinct height response in summer is partly related to different precipitation-type responses occurring at lower and higher elevated regions. All in all, assuming a spatially homogeneous absolute change in precipitation in all seasons, these are the vertical dependencies of the relative changes one would expect.

\subsection{Downscaling procedure}

To make available more localized climate change information, a downscaling procedure has been developed, using the gridded ENSEMBLES mean data and the probabilistic regional scenarios from $\mathrm{CH} 2011$, as described above. Figure 2 shows schematically how the localization 

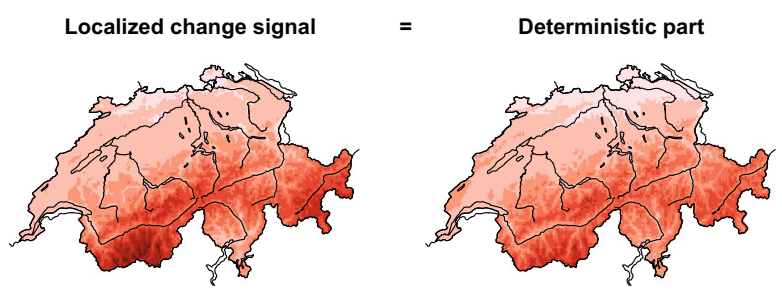

External drift or trend (longitude, latitude, height)

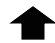

regionally adjusted ENSEMBLES seasonal mean change pattern with $\mathrm{CH} 2011$ estimates seasonal mean change pattern

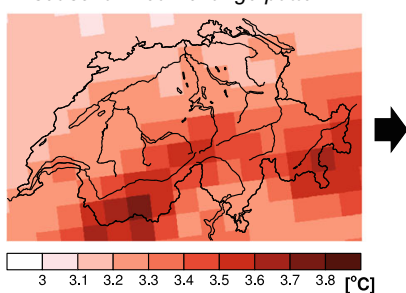

$+\quad$ Stochastic part

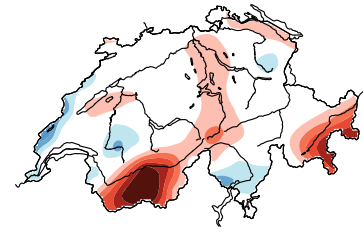

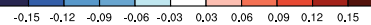

Kriging of residuals (exponential variogram)

Fig. 2 Schematic of downscaling procedure. The method is illustrated for the median probabilistic estimate of temperature change in fall (SON) for the period 2070-99 and scenario A1B

is achieved. As an example, the case for the median probabilistic estimate of temperature change in fall (SON) for the period 2070-99 and scenario A1B is shown.

In a first step, the ENSEMBLES seasonal mean change pattern over Switzerland is adjusted, such that the regional averages correspond to the probabilistic regional estimates of CH2011. Hence, the adjusted fields are grid point anomalies of the ENSEMBLES mean change patterns with respect to the regional estimates. For temperature (precipitation), absolute (relative) differences are used. In case of precipitation, the ratios between the scenario and the reference are downscaled and then transformed back to percentage changes. The adjustments with the CH2011 estimates are small in general for all median estimates of temperature and precipitation because the Bayesian median estimates are very similar to the regional means of the ENSEMBLES data. In addition, the differences between the regional means of $\mathrm{CH} 2011$ and ENSEMBLES are much smaller than the grid point anomalies. For example, the median temperature change signal in the three $\mathrm{CH} 2011$ regions $\mathrm{CHNE}, \mathrm{CHW}$, and $\mathrm{CHS}$ of the A1Bscenario in winter (DJF) in the period $2070-99$ is $3.64{ }^{\circ} \mathrm{C}, 3.61{ }^{\circ} \mathrm{C}$ and $3.83{ }^{\circ} \mathrm{C}(\mathrm{CH} 2011$ 2011), respectively, while the ENSEMBLES mean temperature change signal suggests a warming range of roughly $1{ }^{\circ} \mathrm{C}$ between the lowest and the highest values over Switzerland. Therefore, differences in the regional means between neighboring regions do not lead to problematic artificial features as shown for the example in the schematic.

The resulting change patterns on the coarse grid are downscaled using a Kriging interpolation with external drift (Journel and Huijbregts 1978; Wackernagel 2003). Kriging is the most prominent technique in geostatistics when dealing with relatively small samples (Von Storch and Zwiers 2002). It is the best linear unbiased predictor for spatially correlated data. Kriging with external drift, often also referred to as Universal Kriging, assumes that the downscaled pattern is given by the sum of a deterministic part (regression or trend) and a stochastic part (kriged trend residuals). Kriging with external drift is similar to Ordinary Kriging, except that the covariance matrix is extended with the values of the auxiliary 
predictors. The regression is based on generalized least squares because of spatial correlation in the data.

For an estimation of the deterministic part of the climate change signals, the geographical coordinates longitude, latitude and height on the coarse ENSEMBLES grid are used as predictors. The height of the E-OBS data instead of the ENSEMBLES mean is used here. This is because the orography in the multi-model mean slightly differs prior to and after 2050 due to the unequal number of RCM-GCM-chains. In the ENSEMBLES/E-OBS data the highest values do not exceed 2,600 m asl, whereas the highest Alpine elevations in the 2$\mathrm{km}$ grid are above $4,000 \mathrm{~m}$ asl. The regression is used to extrapolate in this range.

In order to test whether or not height should be included as a linear predictor, likelihood ratio tests were performed for each estimate. The likelihood ratio test compares the likelihood $L$ of two statistical models of different complexity, one of which is nested into the other (Neyman and Pearson 1933). The corresponding test statistic $D$ is twice the ratio of the loglikelihoods of the two models:

$$
D=-2 \ln \left(\frac{L_{0}(\Theta)}{L_{1}(\Theta)}\right)
$$

The probability distribution of $D$ can be approximated with a $\chi^{2}$-distribution with $\left(d f_{0}-d f_{1}\right)$ degrees of freedom, where $d f_{0}$ and $d f_{1}$ are the degrees of freedom of the null model with likelihood function $L_{0}(\Theta)$ and the model of higher complexity denoted by $L_{1}(\Theta)$. Here, the downscaling procedure was once performed with height included and once without. For both temperature and precipitation more than $80 \%$ of p-values is below the $5 \%$-significance level, meaning that the null model (without height) is most often rejected. Therefore, height is needed as an additional predictor to explain the spatial variability of temperature and precipitation change in the (adjusted) ENSEMBLES mean patterns over Switzerland. Note that any higher-order polynomial terms of height do not generally improve the downscaling further and might lead to overfitting.

The kriged residuals can be interpreted as spatially correlated local deviations from the deterministic trend. They build the stochastic component. The spatial correlation is modeled with omnidirectional empirical variograms that are computed individually for each estimate. The fitted exponential variograms are based on maximum likelihood estimation.

For the construction of the localized climate change signals under the greenhouse gas emission scenarios A2 and RCP3PD, the ENSEMBLES mean change patterns have been scaled from A1B with the same pattern-scaling factors as used by (Fischer et al. 2012). The factors for A2 (RCP3PD) are 0.89 (0.95) for the period 2020-49, $0.98(0.60)$ for 2045-74 and $1.17(0.43)$ for 2070-99.

In order to avoid boundary effects to occur within Switzerland in the Kriging step, various grid points outside the country borders are taken into account (see Fig. 1a). Finally, the areas outside of Switzerland in the localized data are removed for further analysis.

\subsection{Proof of concept}

Uncertainties associated with the downscaling procedure are discussed below. Here, the usefulness of the downscaling method with respect to the Kriging step is confirmed with the test illustrated in Fig. 3. The difference between the observed seasonal mean temperature of the two norm periods 1981-2010 and 1961-1990 is considered as a 'perfect model simulation' of past temperature change (Fig. 3a-d). More details on the establishment of the new norm period 1981-2010 is provided by (Begert et al. 2013). The original data for the two periods is given 

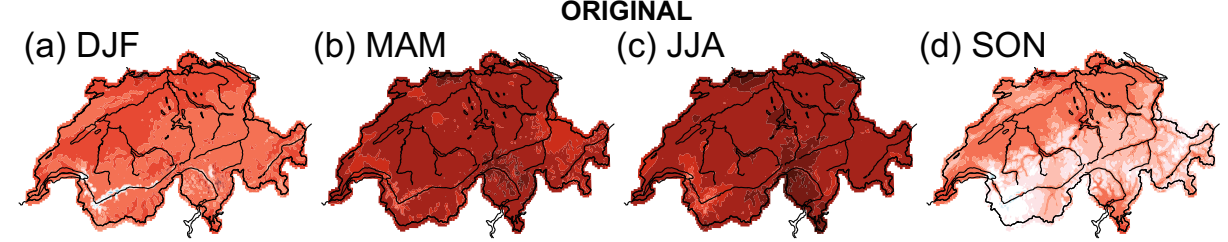

UPSCALED
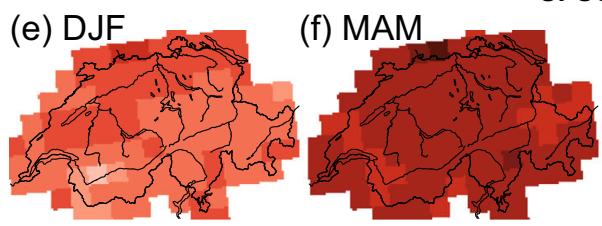

(g) JJA
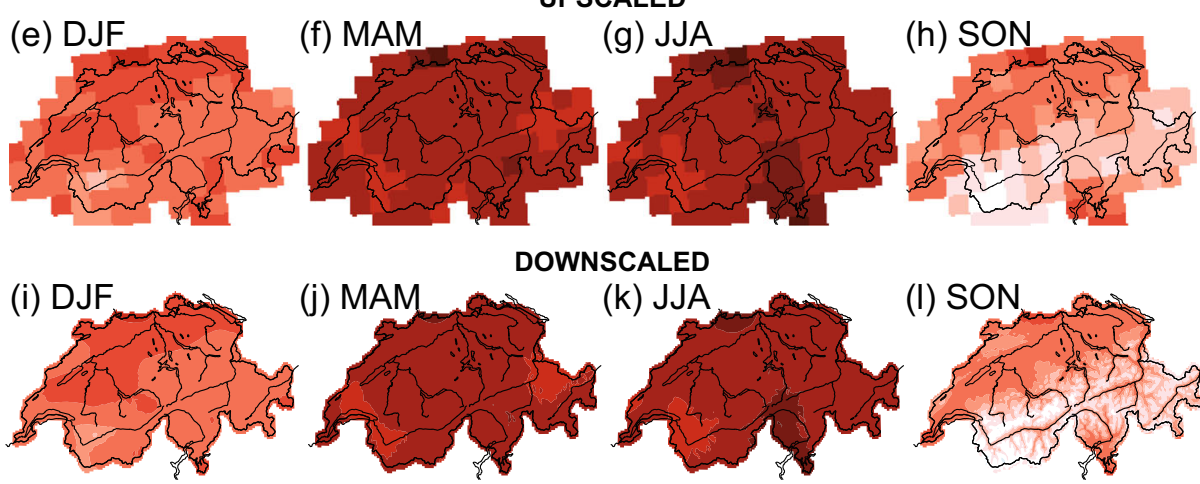

DOWNSCALED
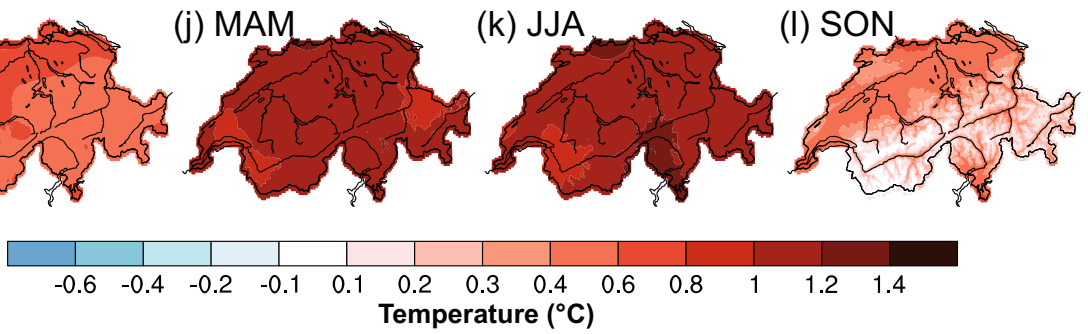

(DOWNSCALED - ORIGINAL)

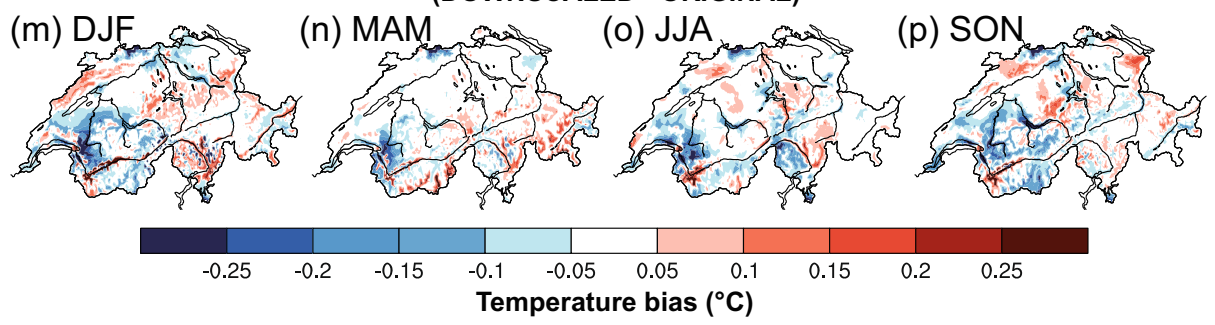

Fig. 3 Seasonal mean temperature change between the period 1981-2010 and 1961-1990 for winter (DJF), spring (MAM), summer (JJA) and fall (SON). Top row (a-d): original data on $0.02^{\circ}$ grid, second row (e-h): original values upscaled to $0.22^{\circ}$ ENSEMBLES grid by grid box averageing, third row (i-l): downscaled values on high-resolution grid, bottom row (m-p): bias of downscaling method (downscaled signal minus original data)

on the high-resolution grid. For this test, the observed change signals were first upscaled by grid cell averageing to the $0.22^{\circ}$ grid of the ENSEMBLES models (Fig. 3e-h) and then downscaled with the Kriging method described above (Fig. 3i-1).

If the downscaling procedure were perfect and all climatological information were available on the coarser grid, the panels in Fig. 3(i-1) would be equal to the respective panels in the top row and the bias would be zero. It is shown that the patterns are roughly reconstructed by the downscaling in all seasons. The kriging step contributes to a considerable degree of smoothing in the lower Rhone valley, where very small-scale features can be discerned in the original data. However, the slightly stronger warming in the Swiss lowlands as compared to the surrounding higher regions is well captured. In addition, the downscaling scheme is able to reproduce the warming pattern in the western Ticino in summer. The bias is largely below $\pm 0.2^{\circ} \mathrm{C}$. 
Good agreement between original and downscaled temperature change pattern is also found in fall (SON). Very small-scale differences, e.g. in the Rhine valley and the surrounding mountains, are quite well reproduced. In the observations, fall is the only season showing a statistically significant height-dependence of the temperature change between the two reference periods. This is in contrast to the projected future change signals from ENSEMBLES, where the height-dependence is significant inmost seasons for both temperature and precipitation as shown above with the likelihood ratio tests. Hence, since a significant heightdependence seems important for a successful downscaling of valley/ridge features, we are confident that for the projected change signals this approach produces reasonable results.

A corresponding proof of concept for precipitation is provided as Supplementary material (Fig. 3). Also for the case of precipitation the changes on the regional scale are well captured by the kriging method. On local scale, the original change pattern in the observations is very patchy as a consequence of changes in station density over time and aspects of interpolation from stations to the 2-km grid. This results in small likelihood values in the kriging method and relatively large local biases of up to $8 \%$.

\subsection{Uncertainties of the downscaling method}

There are several sources of uncertainty in the localized climate change signals. The major source of uncertainty can be traced back to the posterior distribution of the climate change signals obtained from the Bayesian algorithm. The distribution is very sensitive to the prior choice of the model projection uncertainty as shown by (Fischer et al. 2012). The spread between the lower and the upper probabilistic estimate depends on the prior variance assumed. (Fischer et al. 2012) illustrate that depending on the chosen model projection uncertainty and the number of models, a difference in the confidence intervals of $1-5{ }^{\circ} \mathrm{C}$ is possible for temperature. For precipitation, model projection uncertainty also largely contributes to the overall uncertainty. An additional contribution is given by the recombination with internal decadal variability from station observation, as discussed above. As a consequence, the three estimates should not be interpreted in a strictly probabilistic way. They should be considered as three equally likely realizations of temperature or precipitation change in Switzerland (CH2011 2011).

Much smaller uncertainties are induced by the downscaling method on the localized scale. These uncertainties are associated with the stochastic component of the Universal Kriging interpolation onto the 2-km grid. Based on the fitted exponential variograms, the weighting coefficients for the interpolation are computed. They are subject to uncertainty. The Kriging standard deviation can be used as a measure to quantify uncertainties due to the downscaling approach for each individual realization discussed beforehand.

Figure $4 \mathrm{a}-\mathrm{b}$ depict the change signals for the median estimates of temperature and precipitation by the end of the century (2070-99) for the A1B-scenario. The change signals are displayed as average values within height bins of $500 \mathrm{~m}$ thickness. Attached to each mean value is an uncertainty bar. It corresponds to the mean value of the $b i n \pm 1$ Kriging standard deviation. Since the Kriging standard deviation is different for each grid point and by design approaches zero near the grid points of the coarse ENSEMBLES grid, the method strongly constrains the downscaled climate change signals to the patterns found on the coarse grid. This includes regions above 2,600 $\mathrm{m}$ asl, where an extrapolation is done. Hence, the maximum of the standard deviations in each height bin is used in the plot. First of all, this plot shows the strong vertical dependence of the climate change signals in all seasons under the A1B-scenario at the end of the century. Secondly, the uncertainty range defined through the maximal standard deviation in temperature (precipitation) does not exceed $0.3 \mathrm{~K}(4 \%)$ in these cases. 
(a) Change signal for temperature (A1B, 2070-99, median)

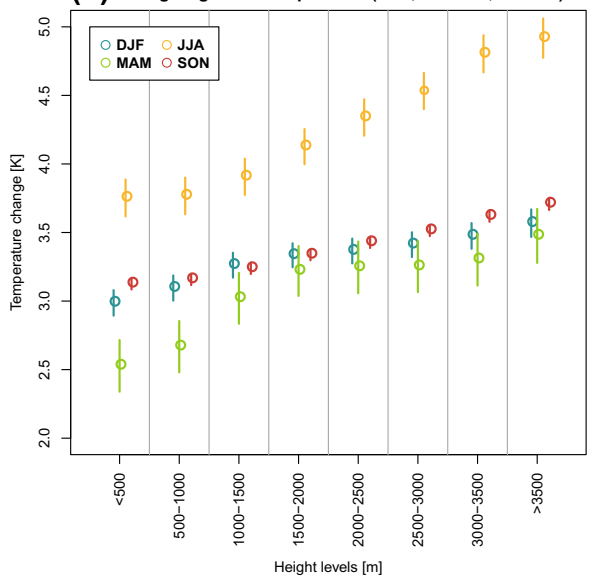

(c) Histogram of Kriging standard deviation (temperature)

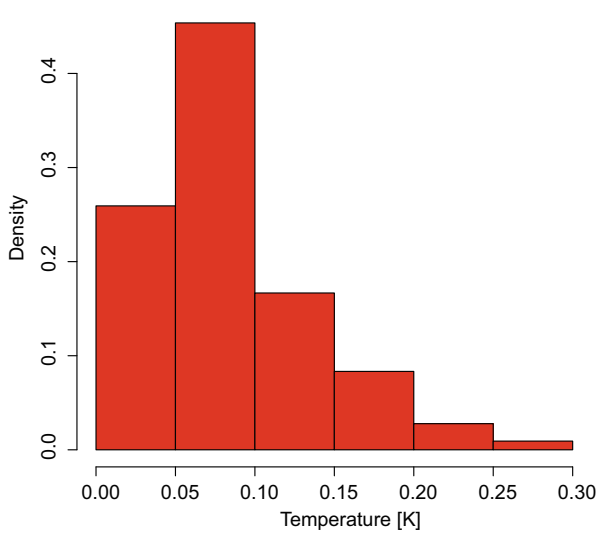

(b) Change signal for precipitation (A1B, 2070-99, median)

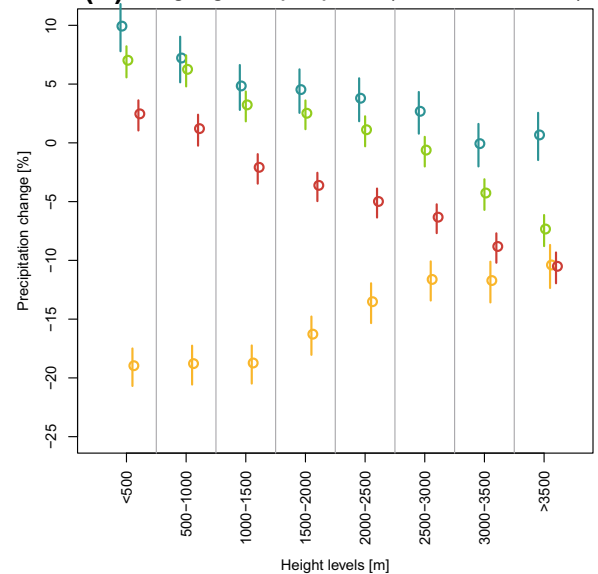

(d) Histogram of Kriging standard deviation (precipitation)

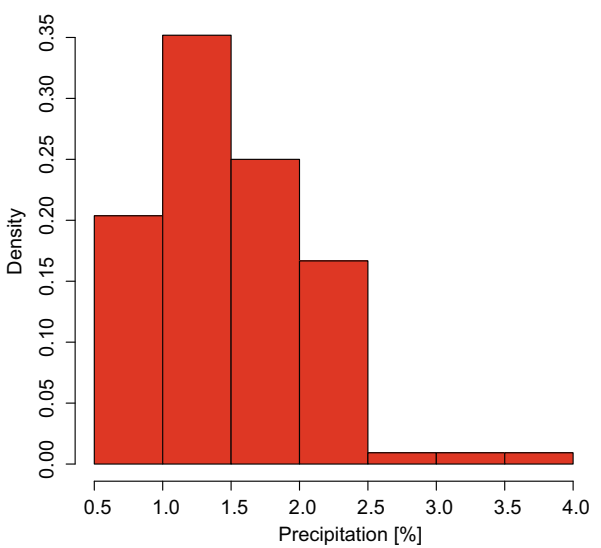

Fig. 4 Change signals for the median estimates of a temperature and $\mathbf{b}$ precipitation by the end of the century (period 2070-99) for the A1B-scenario and histograms of Kriging standard deviation for all estimates of c temperature and $\mathbf{d}$ precipitation. In (a) and (b) the dots correspond to mean values over height bins of $500 \mathrm{~m}$ thickness. The respective lines indicate Kriging uncertainty: the maximal standard deviation of each height bin is added or subtracted from the mean value. The total density in (c) and (d) amounts to 1

Uncertainties tend to be very slightly larger at higher altitudes (mostly less than $+0.03 \mathrm{~K}$ for temperature and $+0.1 \%$ for precipitation). For temperature, the uncertainty of the Kriging step is comparable in magnitude to the bias obtained for the proof of concept with observed the temperature changes. It is also noteworthy that the vertical dependence of the climate change signals is substantially larger in all displayed cases than the respective uncertainty ranges.

Figure $4 c-d$ show histograms over all estimates (all seasons, periods and scenarios) for the maximum Kriging standard deviation over Switzerland for temperature and precipitation. It is obvious that in general the uncertainty associated with the Kriging method is very small. More than $80 \%$ of all estimates have standard deviations of less than $0.15 \mathrm{~K}$ in case of temperature and less than $2 \%$ in case of precipitation. These standard deviations are roughly by a factor 2 to 10 smaller than the vertical dependence when the latter is expressed in terms of maximum distance between largest and smallest change signal for a given estimate. 
Additional uncertainties are connected to the fact that (1) the ENSEMBLES mean pattern is used rather than single model output and that (2) a simple pattern-scaling approach is used for the scenarios A2 and RCP3PD. In order to quantify the uncertainties associated with the use of multi-model mean data (point 1), the downscaled mean pattern was compared against the mean over all models downscaled with the same method. The root mean squared error (RMSE) for the median estimate of scenario A1B (period 2070-99) was found to be $0.04{ }^{\circ} \mathrm{C}\left(0.05{ }^{\circ} \mathrm{C}, 0.11{ }^{\circ} \mathrm{C}, 0.08{ }^{\circ} \mathrm{C}\right)$ for temperature in DJF (MAM, JJA, SON) and $4.1 \%$ $(3.0 \%, 1.4 \%, 4.1 \%)$ in DJF (MAM, JJA, SON) for precipitation. Uncertainties in earlier projection periods are of the same order or smaller. Concerning point (2), (Fischer et al. 2012) found uncertainties of the pattern-scaling procedure in the order of $0.2 \mathrm{~K}$ for temperature and $6 \%$ for precipitation.

\section{Results}

The resulting localized climate change signals for seasonal averages of daily mean temperature are shown in Fig. 5. For the sake of brevity, only the A1B scenario is displayed here. The warming clearly increases towards the end of the 21 st century, from about $1{ }^{\circ} \mathrm{C}$ in $2020-2049$ with respect to the reference period $1980-2009$ to roughly $4{ }^{\circ} \mathrm{C}$ in $2070-2099$ (median estimate). The annual cycle of the change signal for temperature is not pronounced, although a slightly stronger warming is found for the summer season. This finding is independent of the chosen scenario or scenario period. In A1B and A2, the associated model uncertainty of the

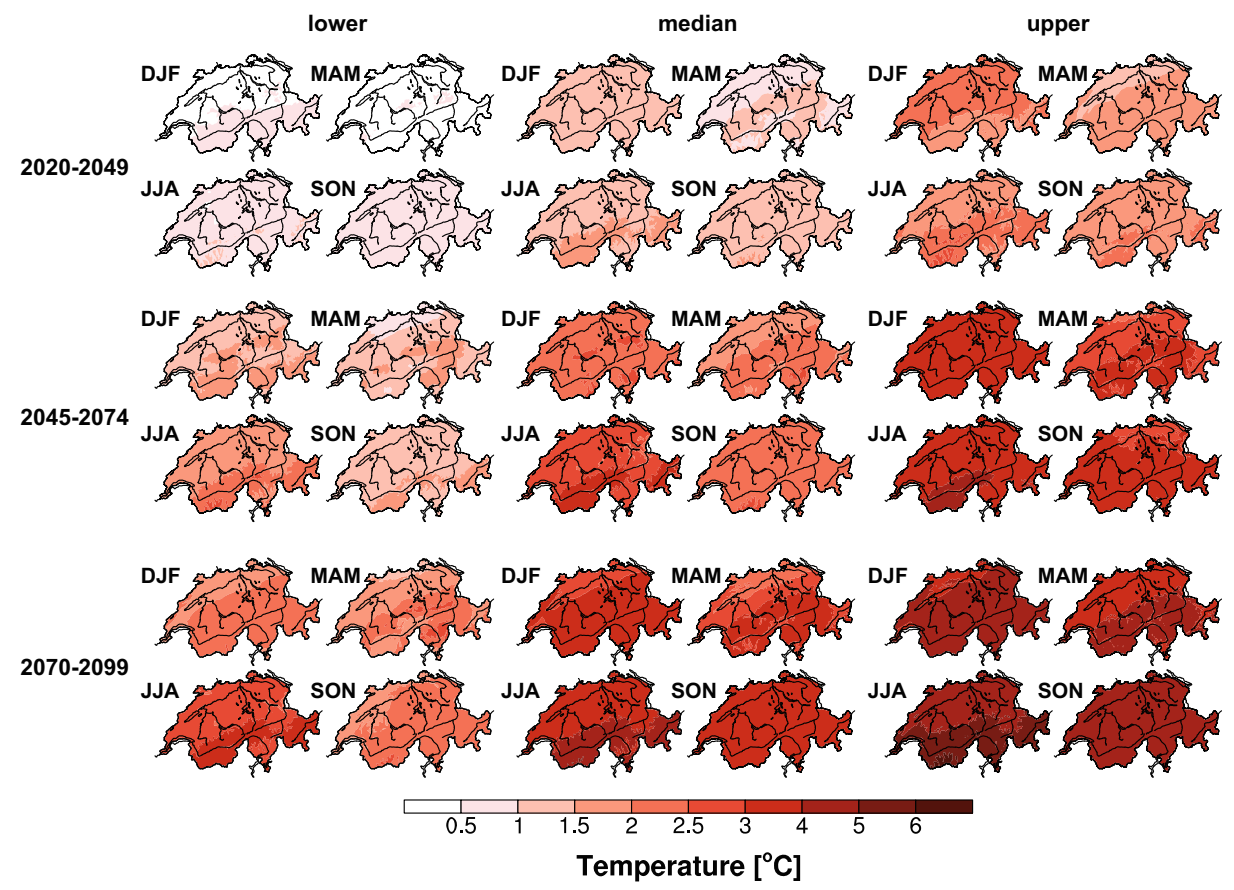

Fig. 5 Localized seasonal mean temperature change signals for the A1B scenario. The lower, median and upper estimate (initially derived from $2.5 \%$-, $50 \%$ - and $97.5 \%$-quantile) for each of the three scenario periods (20202049, 2045-2074, and2070-2099) 
change signal, expressed here by the lower and upper estimate, increases towards the end of the century. In the RCP3PD scenario the change signals hardly differ between the different periods. Note, that by design these results agree with the CH2011 report (CH2011 2011).

The height-dependence of the change signal in the ENSEMBLES models can partly be associated to the snow-albedo feedback and other mechanisms (Ceppi et al. 2012; Kotlarski et al. 2012a). The snow-albedo feedback describes the enhanced warming with less snow due to a darker land surface and the connected increase in absorbed solar radiation at the surface (Im et al. 2011). Thus, the warming is larger at higher altitudes, where the models predict a snow cover decrease in the future (Im et al. 2011; Ceppi et al. 2012; Kotlarski et al. 2012a; Steger et al. 2013). In summer, the warming in 2045-2074 and also 2070-2099 is about $1{ }^{\circ} \mathrm{C}$ larger above 2,500 m asl as compared to the Swiss lowlands with altitudes between 400 and $800 \mathrm{~m}$ asl. This is also confirmed by Fig. 4. The largest difference in space results between the southwestern mountains along the border to Italy and the northeastern lowlands close to Lake Constance. Despite the physical explanation for the enhanced warming at higher altitude in the ENSEMBLES models, one has to be aware that the signal above $2,600 \mathrm{~m}$ asl is a result of the statistical extrapolation.

Given the vertical gradient in warming, the most remarkable difference between the spatially localized dataset and the ENSEMBLES mean pattern can be expected in the Alpine region, with its complex topography including mountains higher than $4,000 \mathrm{~m}$ asl but also deep and narrow valleys with altitudes down to $400 \mathrm{~m}$ asl. One such example is the Rhone river valley that is flanked to both sides by the highest mountains of the Valaisan and the Bernese Alps. This valley is not resolved by the ENSEMBLES models owing to the fact that the valley ground is rather narrow with less than $6 \mathrm{~km}$ width. As an example, in the A1Bscenario in summer during 2070-99 the Rhone river valley warms about $1{ }^{\circ} \mathrm{C}$ less than its highest surrounding peaks (median estimate).

For each probabilistic estimate, the observed and projected temperature values for winter and summer assuming the A1B scenario (2070-99) are given as Supplementary material (Fig. 4). In this approach, the values in the scenario period are simplythe observations shifted by the collocated change signal. The increase in temperature by the end of the century causes a retreat of the zero-degree line towards the core of the Alpine region. It also rises about $400 \mathrm{~m}$ in the median estimate of A1B (2070-99), such that the vast majority of hills north of the Alps may be above $0{ }^{\circ} \mathrm{C}$ mean temperature during winter. In summer, daily average temperatures above $20 \mathrm{C}$ are projected to be normal in the Swiss lowlands, the Rhone river valley, as well as the Ticino.

Figure 6 shows the downscaled climate change signals of mean precipitation for the A1B emission scenario (2070-99) on the 2-km grid. Precipitation change can be both positive or negative. Natural decadal variability that amounts to roughly $\pm 10 \%$ is hardly exceeded in most seasons (CH2011 2011). During the summer season a distinct drying is projected. The summer drying is enhanced towards the end of the century. It is strongest in the western part of Switzerland and south of the Alps. Previous studies suggested that the summer drying in most of southern and central Europe is a consequence of the expansion and weakening of the Hadley cell (Held and Soden 2006; Lu et al. 2007; Mariotti et al. 2008; CH2011 2011) and the associated increase in moisture divergence across the subtropical dry zone in response to the greenhouse gas forcing and the associated stabilization of the tropical and subtropical atmosphere ( $\mathrm{Lu}$ et al. 2007). This is seen in all GCMs of the IPCC fourth Assessment Report (Solomon et al. 2007). In addition, a positive soil-moisture-precipitation feedback is projected to enhance the reduction of convective summer precipitation, and thus, support the northward expansion of the aforementioned dry zone (Rowell and Jones 2006). 


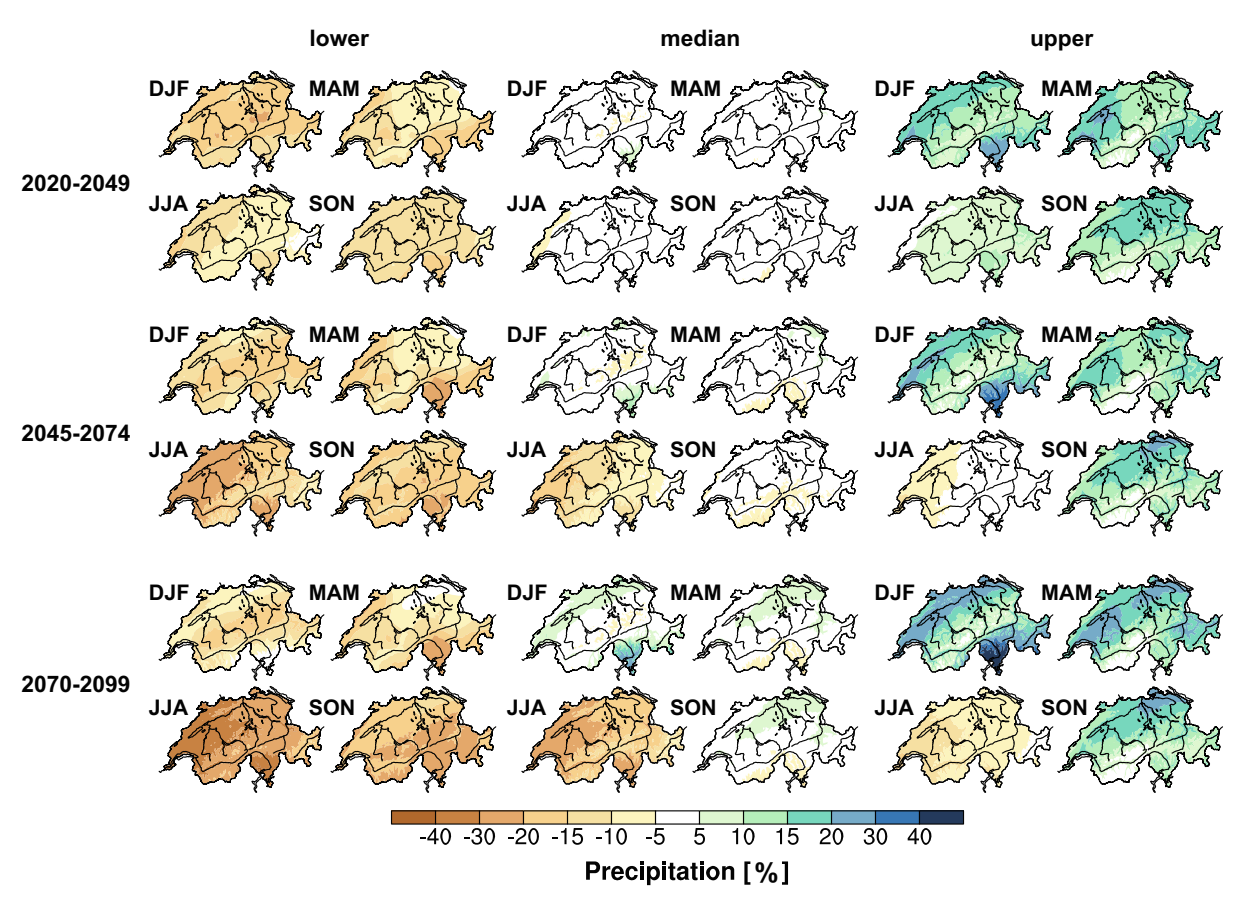

Fig. 6 The same as Fig. 5, but for precipitation (\%)

In winter, a slight precipitation increase in the median estimate in the Swiss lowlands (5$10 \%$ ) and south of the Alps (up to $20 \%$ ) is projected by the end of the century. Possible explanations for the wetter conditions in future winter seasons are the increase in atmospheric moisture content due to the higher water holding capability of the warmer atmosphere and circulation changes.

The observed mean winter and summer precipitation as well as the projected future precipitation using the A1B scenario are shown in the Supplementary material to this article (Fig. 5).

\section{Discussion}

A new spatially localized data set of climate change signals for seasonal mean temperature and precipitation in Switzerland was presented. A Kriging interpolation with external drift was used to downscale the ENSEMBLES mean climate change patterns with a resolution of roughly $25 \mathrm{~km}$ in combination with a Bayesian method for larger regions to a grid with horizontal resolution of about $2 \mathrm{~km}$. Height is used as an auxiliary predictor to take into account the elevation dependence of the climate change signal. This is strongly motivated by the complex topography not represented by the given regional climate models.

The new data set allows to distinguish differences in the mean climate change signal between Alpine valleys and mountain ridges and, thus, facilitates the study of more complex local and regional climate change within Switzerland, e.g. the impact ofthe warming atmosphere on glacier development, river discharge, agricultural and other aspects at a fine horizontal scale. 
We found a distinct altitude-dependence of both temperature and precipitation change signals. The magnitude of the dependence on altitude, however, is different for the four seasons and the three scenario periods. A maximum difference between the lowlands and the highest mountain peaks of about $1{ }^{\circ} \mathrm{C}$ was found for summer in 2045-2074 and 20702099 , likely caused by local feedback processes such as the snow-albedo feedback ((Kotlarski et al. 2012a), e.g.).

We highlighted the benefit of having such a data set for the Alpine region, where the amplitude of the climate change signals can vary between the valleys and the surrounding mountain peaks. However, the present study clearly has limitations. First of all, it relies on seasonal mean quantities. The interannual variability and changes thereof are not considered. Also, the results do not allow statements about changes in temporal correlations on a daily time scale. However, the seasonal mean change signal can directly be applied to daily time series using a delta-change approach. The limitations of such a procedure must be considered though: Altering standard deviations or temporal and spatial correlations are not taken into account, neither are changes in dry or wet spell lengths considered. Furthermore, the presented approach assumes a constant bias, an assumption which may be problematic for some regional climate models run within the ENSEMBLES project (Christensen et al. 2008).

Another limitation is given by the use of height alone as a linear predictor because it is not the only factor affecting climate change in the Alps. There is a relatively large range of altitudes between 2,600 and $4,000 \mathrm{~m}$ asl, where extrapolation is necessary because the ENSEMBLES mean orography does not go beyond 2,600 $\mathrm{m}$ asl. On the one hand, an extrapolation is desired, as studies of warming on high spatial resolution in the Alps have shown an altitude-dependence of the climate change signal ((Im et al. 2011), e.g.), who used a regional climate model at $3-\mathrm{km}$ resolution. On the other hand, extrapolation is used for data imputation at locations, where no data is available in the input data set, and thus, local-scale changes in individual grid cells must be treated carefully. Also, the choice of the downscaling method and the parameter estimation add uncertainty that has to be quantified. In this study, the largest source of uncertainty for the climate change signals is induced by the ensemble of RCMs and is largely determined by the prior assumptions made within the Bayes algorithm (model projection uncertainty).

Uncertainties associated with the Kriging method and the choice of the ENSEMBLES mean patterns rather than single model output were found to be comparatively small. Kriging standard deviations are of the order of $0.1 \mathrm{~K}$ for temperature or $2-4 \%$ and less for precipitation. Thus, we have confidence that the method chosen for localization of the height-dependent climate change signals produces reasonable and robust results.

When using the data set, one should keep in mind that the three seasonal estimates provided for each scenario and projection period should be interpreted as equally likely realizations of climate change rather than events with a certain probability. In addition, potential users should be aware that temperature and precipitation were downscaled independently of each other in this study. Further studies should treat temperature and precipitation in a bivariate approach to make sure that correlations between the two quantities are taken into account. Nevertheless, despite the abovementioned uncertainties and limitations the new data set enables a variety of interesting studies of local climate change in Switzerland. An application of the data set for a number of relevant climate change indices is provided by (Zubler et al. 2014).

Acknowledgments The author wishes to thank the anonymous reviewers for their valuable comments. The $\mathrm{CH} 2011$ data were obtained from the Center for Climate Systems Modeling (C2SM). The ENSEMBLES data 
used in this work was funded by the EU FP6 Integrated Project ENSEMBLES(Contract number 505539) whose support is gratefully acknowledged. The Swiss Federal Office for the Environment (FOEN) is partly financing the present study.

Open Access This article is distributed under the terms of the Creative Commons Attribution License which permits any use, distribution, and reproduction in any medium, provided the original author(s) and the source are credited.

\section{References}

Baeriswyl PA, Rebetez M (1997) Regionalization of precipitation in Switzerland by means of principal component analysis. Theor Appl Climatol 58:31-41

Begert M (2008) Repräsentativität der Stationen im Swiss National Basic Climatological Network. Arbeitsberichte der MeteoSchweiz 217, MeteoSwiss

Begert M, Schlegel T, Kirchhofer W (2005) Homogeneous temperature and precipitation series of Switzerland from 1864 to 2000. Int J Climatol 25:65-80

Begert M, Frei C, Abbt M (2013) Einführung der Normperiode 1981-2010. Fachbericht 245, MeteoSchweiz

Beniston M, Rebetez M (1996) Regional behavior of minimum temperatures in Switzerland for the period 19791993. Theor Appl Climatol 53:231-244

Buser CM, Künsch HR, Lüthi D, Wild M, Schär C (2009) Bayesian multi-model projections of climate: bias assumptions and interannual variability. Clim Dyn 33:849-868. doi:10.1007/s00382-009-0588-6

Casella G, George E (1992) Explaining the Gibbs sampler. Am Stat 46(3):167-174

Ceppi P, Scherrer SC, Fischer A, Appenzeller C (2012) Revisiting Swiss temperature trends 1959-2008. Int J Climatol 32:203-213. doi:10.1002/joc.2260

CH2011 (ed) (2011) Swiss Climate Change Scenarios CH2011. C2SM, MeteoSwiss, ETH, NCCR Climate, and OcCC, Zurich, Switzerland

Christensen JH, Boberg F, Christensen OB, Lucas-Picher P (2008) On the need for bias correction of regional climate change projections of temperature and precipitation. Geophys Res Lett 35(L20709), doi:10.1029/ 2008GL035694

Fischer EM, Schär C (2010) Consistent geographical patterns of changes in high-impact European heatwaves. Nat Geosci 3:398-403. doi:10.1038/ngeo866

Fischer AM, Weigel AP, Buser CM, Knutti R, Künsch HR, Liniger MA, Schär C, Appenzeller C (2012) Climate change projections for Switzerland based on a bayesian multi-model approach. Int J Climatol 32(15):23482371. doi:10.1002/joc.3396

Fischer AM, Keller DE, Liniger MA, Rajczak J, Schär C, Appenzeller C (2014) Projected changes in precipitation intensity and frequency in Switzerland: a multi-model perspective. submitted to Int J Climatol

FOEN (2012) Adaptation to climate change in Switzerland - goals, challenges and fields of action: First part of the Federal Council's strategy. Tech. rep., Federal Office for the Environment

Frei C (2013) Interpolation of temperature in a mountainous region using non-linear profiles and non-euclidean distances. Int J Climatol. doi:10.1002/joc.3786

Giorgi F, Hurrell JW, Marinucci MR (1997) Elevation dependency of the surface climate change signal: a model study. J Clim 10:288-296

Haylock MR, Hofstra N, Tank AMGK, Klok EJ, Jones PD, New M (2008) A European daily high-resolution gridded data set of surface temperature and precipitation for 1950-2006. J Geophys Res 113(D20119), DOI 10.1029/2008jd010201

Held IM, Soden BJ (2006) Robust responses of the hydrological cycle to global warming. J Climate 19:56865699, http://dx.doi.org/10.1175/JCLI3990.1

Im ES, Coppola E, Giorgi F, Bi X (2011) Local effects of climate change over the alpine region: A study with a high resolution regional climate model with a surrogate climate change scenario. Geophys Res Lett 37(5), doi:10.1029/2009GL041801

Jasper K, Calanca P, Gyalistras D, Fuhrer J (2004) Differential impacts of climate change on the hydrology of two alpine river basins. Clim Res 26:113-129

Journel AG, Huijbregts C (1978) Mining geostatistics. Academic, New York

Köplin N, Viviroli D, Schädler B, Weingartner R (2010) How does climate change affect mesoscale catchments in Switzerland? - a framework for a comprehensive assessment. Adv Geosci 27:111-119. doi:10.5194/ adgeo-27-111-2010 
Kotlarski S, Bosshard T, Lüthi D, Pall P, Schär C (2012a) Elevation gradients of European climate change in the regional climate model COSMO-CLM. Clim Chang 112:189-215. doi:10.1007/s10584-011-0195-5

Kotlarski S, Lüthi D, Schär C (2012b) The dependence of 21st century European climate change on surface elevation - an RCM ensemble analysis. In: EGU General Assembly, European Geophysical Union (EGU), Vienna, Austria, p 4356

Lu J, Vecchi G, Reichler T (2007) Expansion of the Hadley cell under global warming. Geophys Res Lett 34(6): L06,805

Mariotti A, Zeng N, Yoon JH, Artale V, Navarra A, Alpert P, Li LZX (2008) Mediterranean water cycle changes: transition to drier 21 st century conditions in observations and CMIP3 simulations. Environ Res Lett $3(044001)$

Meehl GA, Stocker TF, Collins WD, Friedlingstein P, Gaye AT, Gregory JM, Kitoh A, Knutti R, Murphy JM, Noda A, et al. (2007) Climate Change 2007: The Physical Science Basis. Contribution of Working Group I to the Fourth Assessment Report of the Intergovernmental Panel on Climate Change, Cambridge University Press, 32 Avenue of the Americas, New York, NY 10013-2473, USA, chap Chapter 10: Global climate projections, pp 747-845

Meinshausen M, Smith SJ, Calvin KV, Daniel JS, Kainuma MLT, Lamarque JF, Matsumoto K, Montzka SA, Raper SCB, Riahi K, Thomson AM, Velders GJM, van Vuuren D (2011) The RCP greenhouse gas concentrations and their extension from 1765 to 2300. Clim Chang. doi:10.1007/s10584-011-0156-z, Special Issue

Neyman J, Pearson ES (1933) On the problem of the most efficient tests of statistical hypotheses. Philos Trans R Soc A: Math Phys Eng Sci 231:289-337. doi:10.1098/rsta.1933.0009.JSTOR91247

Rangwala I, Miller JR (2012) Climate change in mountains: a review of elevation-dependent warming and its possible causes. Clim chang 114(3-4):527-547

Rebetez M, Reinhard M (2011) Monthly air temperature trends in Switzerland 1901-2000 and 1975-2004. Theor Appl Climatol 91:27-34. doi:10.1007/s00704-007-0296-2

Rowell DP, Jones RG (2006) Causes and uncertainty of future summer drying over Europe. Clim Dyn 27(2-3): 281-299

Schär C, Vidale PL, Lüthi D, Frei C, Häberli C, Liniger MA, Appenzeller C (2004) The role of increasing temperature variability in European summer heatwaves. Nature 427(6972):332-336

Scherrer S, Ceppi P, Croci-Maspoli M, Appenzeller C (2012) Snow-albedo feedback and Swiss spring temperature trends. Theor Appl Climatol 110(4):509-516

Schmidli J, Frei C (2005) Trends of heavy precipitation and wet and dry spells in Switzerland during the 20th century. Int J Climatol 25:753-771. doi:10.1002/joc.1179

Schüepp M, Gensler G (1980) Klimaregionen der Schweiz. In: Müller G (ed) Die Beobachtungsnetze der Schweizerischen Meteorologischen Anstalt, no. 93 in Arbeitsbericht der Schweizerischen Meteorologischen Zentralanstalt, Schweizerische Meteorologische Anstalt, Zürich

Solomon S, Qin D, Manning M, Chen Z, Marquis M, Averyt K, Tignor M, Miller H (eds) (2007) Climate Change 2007: The Physical Science Basis. Contribution of Working Group I to the Fourth Assessment Report of the Intergovernmental Panel on Climate Change. Cambridge University Press, 32 Avenue of the Americas, New York, NY 10013-2473, USA

Steger C, Kotlarski S, Jonas T, Schär C (2013) Alpine snow cover in a changing climate: a regional climate model perspective. Clim Dyn 41:735-754

van der Linden P, Mitchell JFB (2009) ENSEMBLES: climate change and its impacts: summary of research and results from the ENSEMBLES project. Met Office Hadley Centre, Exeter. doi:10.1029/2004GL020255

Von Storch H, Zwiers FW (2002) Statistical analysis in climate research. Cambridge University Press

Wackernagel H (2003) Multivariate geostatistics. Springer

Zubler EM, Scherrer SC, Croci-Maspoli M, Liniger MA, Appenzeller C (2014) Key climate indices in Switzerland; expected changes in a future climate. Clim Change pp 1-17, doi:10.1007/s10584-0131041-8, URL http://dx.doi.org/10.1007/s10584-013-1041-8 